\title{
Epidemiology and chronobiology of out-of-hospital cardiac arrest in a subpopulation of southern Poland: A two-year observation
}

\author{
Stanislaw Szczerbinski ${ }^{1}$, Jakub Ratajczak ${ }^{2}$, Piotr Lach $^{2}$, Jakub Rzeszuto ${ }^{2}$, \\ Przemyslaw Paciorek ${ }^{2}$, Joanna Karlowska-Pik ${ }^{3}$, Bartosz Ziemkiewicz ${ }^{3}$, \\ Malgorzata Jasiewicz ${ }^{2}$, Aldona Kubica ${ }^{4}$ \\ ${ }^{1}$ Emergency Medical Center in Opole, Poland \\ ${ }^{2}$ Department of Cardiology and Internal Medicine, Nicolaus Copernicus University, \\ Collegium Medicum in Bydgoszcz, Poland \\ ${ }^{3}$ Department of Probability Theory and Stochastic Analysis, \\ Nicolaus Copernicus University, Torun, Poland \\ ${ }^{4}$ Department of Health Promotion, Nicolaus Copernicus University, \\ Collegium Medicum in Bydgoszcz, Poland
}

\begin{abstract}
Background: Although recent studies indicate temporal variations in the incidence of out-of-hospital cardiac arrest (OHCA), the Polish experience in this research is scarce to date. We evaluated the epidemiology of OHCA and circadian, weekly and seasonal variations of OHCA frequency among the adult population of the Opole district, Poland.

Methods: The retrospective analysis of 815 OHCA cases with presumed cardiac etiology was made based on dispatch cards from the Emergency Medical Center in Opole registered during a 2 year period (2006-2007).

Results: The incidence of $\mathrm{OHCA}$ in the studied population was 1.56/1000 inhabitants per year. Mean age of the group was $69.2 \pm 14.2$ years, with the majority of men (63\%), younger than women (66.1 vs. 74 years, $p=0.0001$ ). The OHCA occurrence increased with age reaching a peak between 71 and 75 years. The incidence of OHCA stayed at stable low levels between 22:00 and 4:59 and started to increase at 5:00, with trimodal peaks: 8:00-10:59, 14:00-15:59 and 18.00-21.59. The lowest number of OHCA occurred from 00:00 to 5:59, the highest from 6:00 to 11:59 (13\% vs. 32.4\%, $p<0.001$ ). The day with the lowest occurrence of OHCA was Friday, the highest Saturday $(10.9 \%$ vs. $16 \%, p=0.01)$. Summer was the season of the lowest incidence of OHCA, while winter - the highest $(22.6 \%$ vs. $26 \%, p=0.04)$. These seasons were the warmest and the coldest one, respectively (average temperature $18.5^{\circ} \mathrm{C} v s .0^{\circ} \mathrm{C}$, $p<0.001$ ).

Conclusions: Circadian and less marked, weekly variability in OHCA occurrence were confirmed. Existing seasonal differences may be affected by temperature. This is the first Polish analysis of a large subpopulation, which also includes seasonal temperature data. (Cardiol J 2020; 27, 1: 16-24)

Key words: circadian, weekly, seasonal, cardiac arrest, variability
\end{abstract}

Address for correspondence: Malgorzata Jasiewicz, MD, PhD, Department of Cardiology and Internal Medicine, University Hospital No. 1, ul. M. Sklodowskiej-Curie 9, 85-094 Bydgoszcz, Poland, tel/fax: +4852585 4023 / +4852 5854024 , e-mail: jasiewiczm@gmail.com

Received: 9.10.2017 Accepted: 1.03.2018 


\section{Introduction}

Out-of-hospital cardiac arrest (OHCA) constitutes a significant medical issue because of both its unexpected characteristics and still low survival rate. The occurrence of cardiac arrest in Europe is estimated as $0.5-1$ per 1000 inhabitants per year [1] while in Poland it is approximately 1.7 per 1000 inhabitants [2]. The majority of patients with OHCA represents a cardiac etiology [3].

There exists an impact of rhythmical factors on humans physiology, and therefore its effects on human health have been demonstrated in many studies. The diurnal variations of blood pressure $[4,5]$, vascular tone [5], urinary catecholamines levels [6], endothelial function, and circulating levels of humoral signals [5], were described in various studies. The levels of plasma cortisol [6], and fibrinogen [7] showed weekly variations and blood pressure [6] with the plasma fibrinogen [7] level have presented seasonal variations in previous studies. The relationship between the chronological factors and the occurrence of acute cardiac events was noted [8]. Previous studies have shown temporal variability in the rate of acute cardiac events, depends on the hour of day $[9,10]$, day of week [9], month [11], season [9, 11], and day of public holidays (e.g. Christmas, New Year's Day) [12]. Time variations have also been demonstrated for the incidence of cardiac arrest, including circadian, circaseptan and circannual variability in the frequency of OHCA [9]. Environmental factors such as cold temperature and higher snowfall have been hypothesized to affect OHCA risk however studies exploring seasonal variability of the occurrence of OHCA in various places around the world have given diverse results [9, 13-15]. Although recent studies indicate chronological variations of $\mathrm{OHCA}$ incidence but to date, Polish experience is scarce. Knowledge about trends in the occurrence of OHCA in a particular population may facilitate the development of management strategies aimed at improving survival. With this regard, objective assessment can only be made by collective reports of data from particular populations and territories as well as their comparisons.

Therefore, the aim of this study was to examine the epidemiology of OHCA as well as temporal variations in the incidence of OHCA (in terms of hour of the day, day of the week, month of the year and season) among the adult population of Opole district, Poland.

\section{Methods}

A retrospective analysis was performed of dispatch cards from Emergency Medical Services (EMS) in Opole (Poland) covering a 2-year period from January $1^{\text {st }}, 2006$ to December $31^{\text {th }}, 2007$. Dispatch cards were compatible with the Utstein template. Cards without data regarding the study criteria were not considered for analysis. Opole district is located in the south of Poland. According to the Statistical Office in Opole $[16,17]$ the district occupies $1683 \mathrm{~km}^{2}$ and during the study period it was inhabited by approximately 262,000 citizens (47.8\% of men). The district includes $129 \mathrm{~km}^{2}$ of urban areas inhabited by $56 \%$ of the population and $1554 \mathrm{~km}^{2}$ of suburban areas.

During the time analyzed there were 47,549 ambulance departures, including 870 (1.83\%) departures due to OHCA. An OHCA was defined as an event with obvious cardiac arrest features happening suddenly and unexpectedly and the mechanism of cardiac arrest was set based on the first recorded heart rhythm: shockable (ventricular fibrillation [VF] or ventricular tachycardia [VT]) or non-shockable (asystole or pulseless electrical activity [PEA]). Patients with traumatic OHCA $(\mathrm{n}=47)$ and under 18 years old $(n=7)$ were excluded from the analysis. Patients with late signs of death, defined by the presence of decomposition, rigor mortis or livor mortis were also excluded. A total of 815 OHCA cases (406 subjects in 2006 and 409 in 2007) were selected for the study.

The circadian variation was evaluated among 24, 1-hour intervals, and four 6-hour time blocks: 'night'(0:00-5:59), 'morning' (6:00-11:59), 'afternoon' (12:00-17:59) and 'evening' (18:00-23:59). In order to maintain comparability a similar pattern of division was used as in previous reports. The weekly variation was analyzed for days of the week. The marginal week days (Saturday, Sunday, Monday) were compared with middle week days (Tuesday, Wednesday, Thursday, Friday). Two definitions of season were used: meteorological season (Spring: March, April, May. Summer: June, July, August. Autumn: September, October, November. Winter: December, January, February) and astronomical season (Spring: 21.03-21.06, Summer: 22.06-22.09, Autumn: 23.09-21.12, Winter: 22.12-20.03).

\section{Statistical analysis}

The normality for all variables was verified with the Shapiro-Wilk test. Data are expressed 
as mean \pm standard deviation (SD) for continuous variables and as counts (percentages) for categorical variables. Statistical analysis was performed using $\chi^{2}$ test for categorical variables and t-Student or Mann-Whitney U test for continuous data depending on distribution. For analysis of more than two variables ANOVA or Kruskal-Wallis test was performed as appropriate according to data distribution. The comparison of groups divided by gender (males vs. females) and age ( $\leq 65$ years vs. $>65$ years) was made. We assumed, in concordance with other reports that people aged 65 years or less are more likely to be pre-retirement and are part of the workforce. For all subgroups we checked circadian, weekly, monthly and seasonal variability. Statistical significance level was adopted for $\mathrm{p}<0.05$. Analysis was performed using IBM SPSS Statistics version 23.

\section{Results}

\section{General characteristics}

The incidence of OHCA in the present population was 1.56 per 1000 inhabitants per year. The above mentioned parameter for men and women accounted for 2.02 and 1.09 per 1000 inhabitants per year, respectively $(\mathrm{p}<0.001)$. Of the 815 OHCA cases, the majority were men $(63 \%, \mathrm{p}=0.0001)$. The mean patient age was $69.2 \pm 14.2$ years. Addi-
Table 1. Basic characteristics of the studied population.

\begin{tabular}{lc}
\hline Variable & Studied population \\
\hline Number of cases & 815 \\
Mean age [years] & $69.2 \pm 14.2$ \\
Male sex & $63 \%$ \\
Initial rhythm: & \\
Asystole & $87.8 \%$ \\
VT/VF & $11 \%$ \\
Location: & \\
Urban & $63.7 \%$ \\
Suburban & $36.3 \%$ \\
\hline
\end{tabular}

VT/VF — ventricular tachycardia/ventricular fibrillation

tional information regarding the studied population is presented in Table 1. Men suffering from OHCA were younger than women $(66.1 \pm 13.4$ vs. $74 \pm$ \pm 14.1 years, $p=0.0001)$. OHCA incidence increased with age, reaching a peak in the $71-75$ age group (Fig. 1). Non shockable rhythm (asystole, PEA) was diagnosed in $88.71 \%$ cases, whereas shockable rhythm (VF or VT) was present in $11.04 \%$ patients. There were no statistical differences regarding initial OHCA rhythms between men and women. The higher occurrence of OHCA

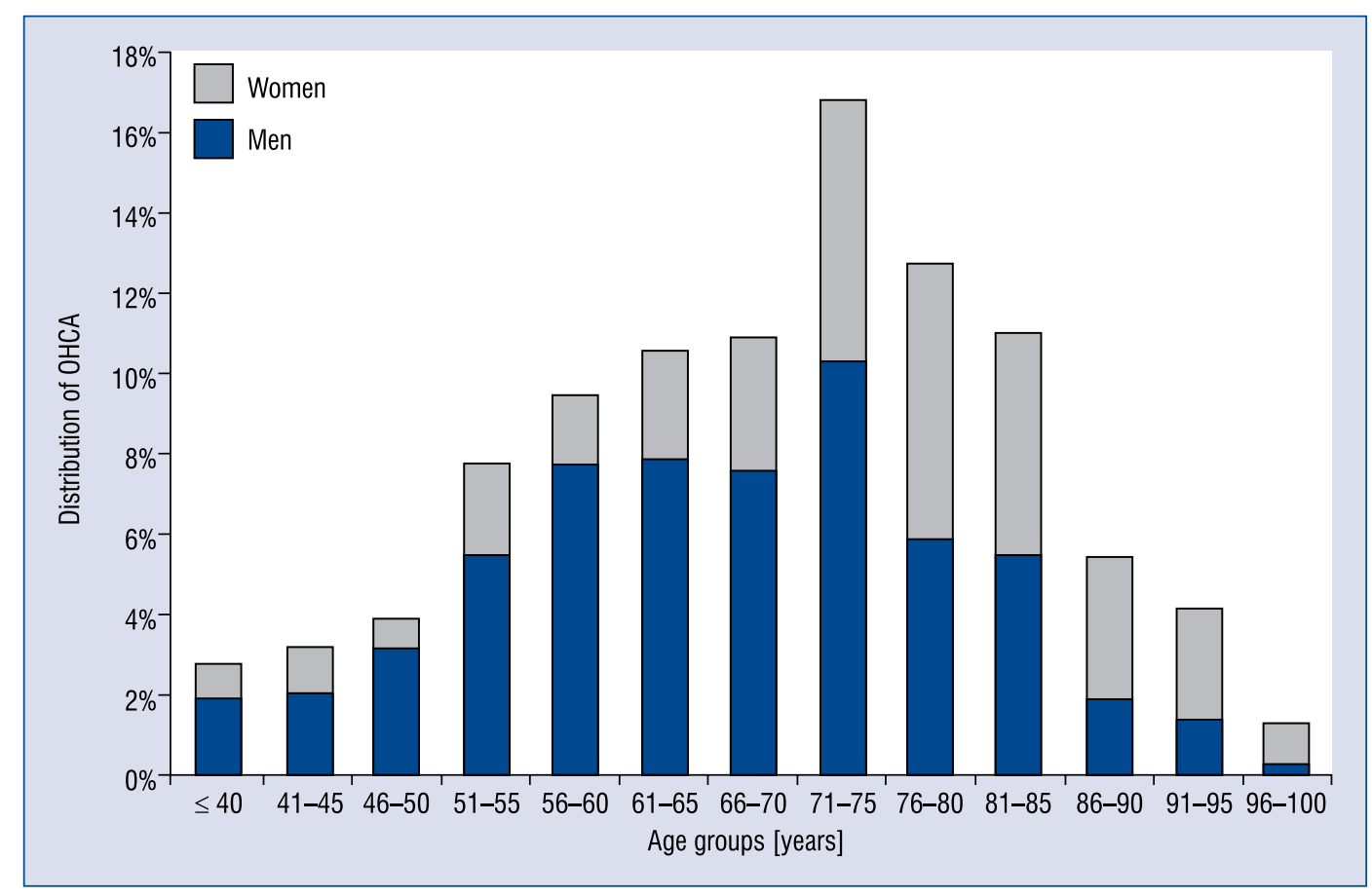

Figure 1. Distribution of out-of-hospital cardiac arrest (OHCA) occurrence depending on age group and gender categories. 


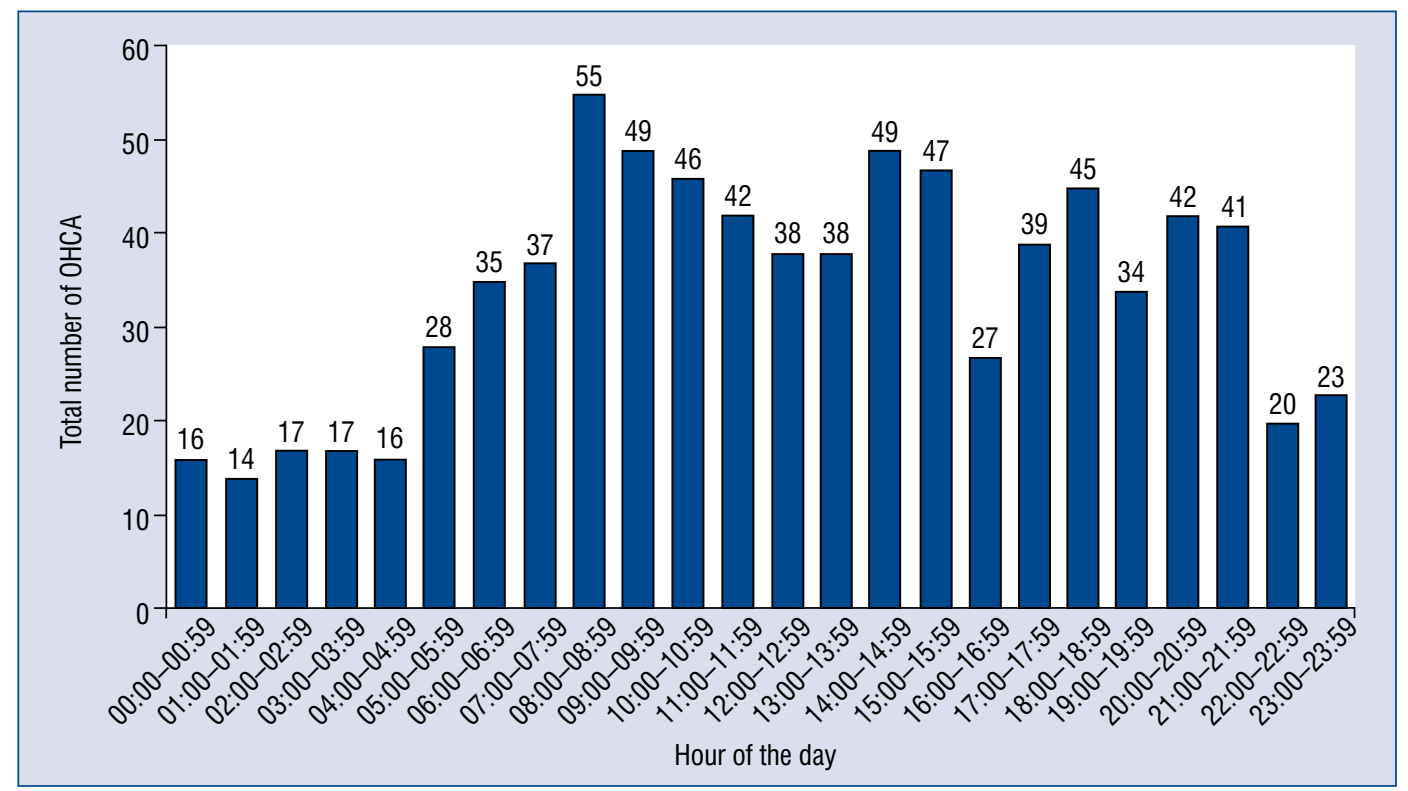

Figure 2. Circadian distribution of out-of-hospital cardiac arrest (OHCA) occurrence divided into 1-hour periods within 24 hours.

was observed in the population aged $>65$ years $(53.4 \%, \mathrm{p}<0.001)$. The subgroup of patients younger than 65 years old had a higher proportion of men $(74.8 \%$ vs. $51.3 \%, \mathrm{p}<0.001)$ and more frequently was diagnosed with VF or VT $(13.7 \%$ vs. $7.6 \%, \mathrm{p}=0.008)$. The majority $(63.68 \%, \mathrm{p}<$ 0.001 ) of OHCAs took place in urban areas.

\section{Circadian variation of $\mathrm{OHCA}$}

Figure 2 shows the histogram of the circadian distribution of OHCA. It demonstrates progressive increase in the incidence of OHCA from 05:00 am with trimodal daily peak: between 8:00 and 10:59 am and between 14:00 and 15:59, less marked 18:00-21:59. It also shows a night time nadir, when the incidence of OHCA stayed at a relatively stable, low level (22:00-4:59). After division into 6-hour intervals (Fig. 3) the lowest number of OHCA occurred at 'night' (00:00-05:59 am; $\mathrm{n}=108,13 \%$, $\mathrm{p}<0.001$ ), while the highest number was noted in the 'morning' period (6:00-11:59 am; $\mathrm{n}=264$, $32.4 \%$ ). It was also a significantly higher number of OHCA in comparison to the 'evening' period $(\mathrm{n}=205, \mathrm{p}=0.046)$, but not to the 'afternoon' period $(\mathrm{n}=238, \mathrm{p}=0.8)$. The circadian variation characterized by the lowest number of OHCA occurring at 'night' was observed both in men $(p=0.001)$ and women $(p=0.002)$, and there was no difference between both gender groups. The circadian variation of OHCA in both age subgroups $(\leq 65$ years vs. $>65$ years) presented the similar

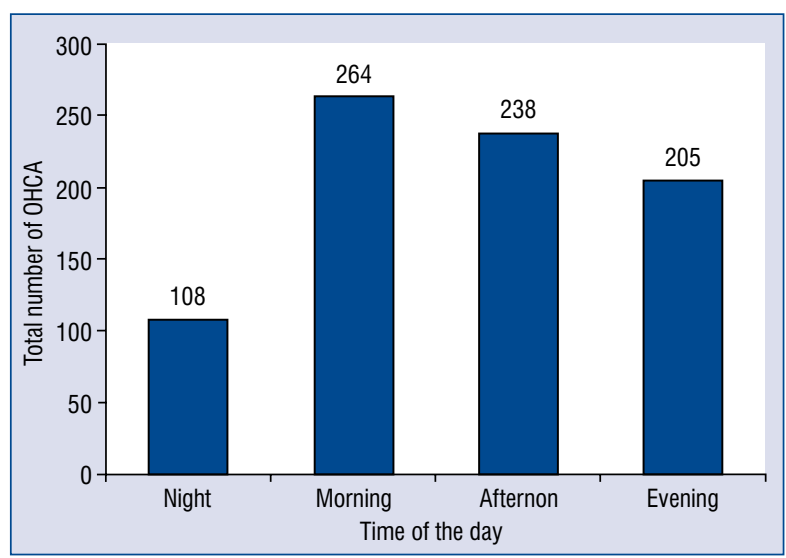

Figure 3. Number of out-of-hospital cardiac arrest (OHCA) in 6-hour intervals within 24 hours. Night vs. Morning: $p<0.001$; Night vs. Afternoon: $p<0.001$; Night vs. Evening: $p<0.001$; Morning vs. Evening: $p=0.046$.

pattern of occurrence as described for the entire group, with a morning peak and a night-time nadir $(\mathrm{p}<0.001)$.

\section{Weekly variation of $\mathrm{OHCA}$}

The lowest number of OHCA was noted on Friday ( $\mathrm{n}=89,10.9 \%$, Fig. 4 ) while the highest on Saturday $(\mathrm{n}=131,16.1 \%, \mathrm{p}=0.01)$, Sunday $(\mathrm{n}=124,15.2 \%, \mathrm{p}=0.02)$, and Monday $(\mathrm{n}=128$, $15.7 \%, \mathrm{p}=0.01)$. The OHCA occurrence was de- 


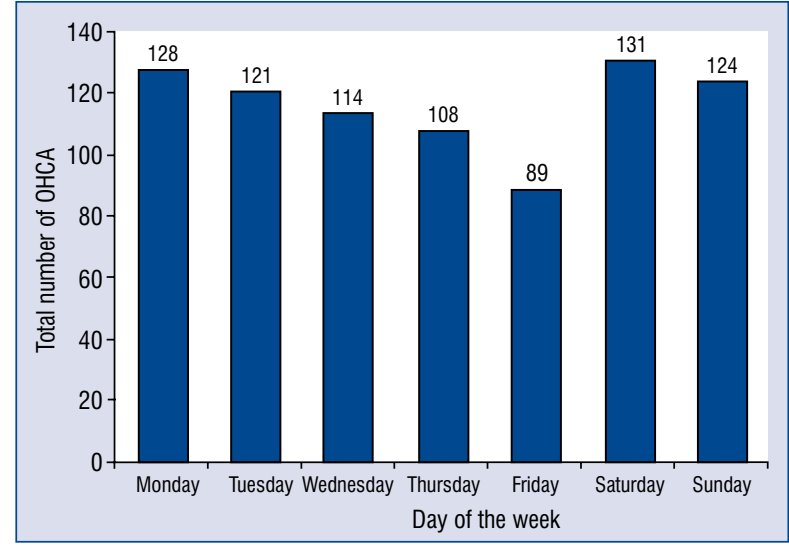

Figure 4. Distribution of out-of-hospital cardiac arrest (OHCA) occurrence in subsequent days of the week; $p=0.11$. Friday vs. Saturday: $p=0.013$; Friday vs. Sunday: $p=0.024$; Friday vs. Monday: $p=0.01$; Saturday, Sunday, Monday vs. Tuesday, Wednesday, Thursday, Friday: $p=0.021$.

creasing gradually from Monday to Friday, however the variability in subsequent days did not reach statistical significance $(\mathrm{p}=0.11)$. OHCA was noticed more often on marginal week days than on middle week days $(\mathrm{p}=0.021)$.

With respect to age subgroups, the lowest number of OHCA events occurred on Friday, both in the group $\leq 65$ years old and older, but the statistical significance was achieved only in the non-elderly group $(\mathrm{p}=0.03)$.

\section{Monthly and seasonal variation of $\mathrm{OHCA}$}

Figure 5 shows monthly distribution of mean daily number of OHCA. August was the month with the lowest average amount of OHCA, October and February - the highest (0.77 vs. 1.26 and 1.25 cases, $p=0.03$ and $p=0.02$, respectively), however the variability in subsequent months was statistically insignificant $(\mathrm{p}=0.3)$. Division to astronomical and meteorological seasons gave us different results (Fig. 6). Although there was no significant difference in seasonal variability of OHCA occurrence in either astronomical $(p=0.16)$ or meteorological $(\mathrm{p}=0.35)$ seasons, a significant difference was noticed between astronomical winter and summer. Astronomical summer was the season of the lowest incidence of OHCA, while winter - the highest $(22.6 \%$ vs. $26 \%, \mathrm{p}=0.04)$. These seasons were the warmest and the coldest one, respectively (average temperature 18.5 vs. $0^{\circ} \mathrm{C}, \mathrm{p}<0.001$, Fig. 6$)$. In both age groups as well as gender groups the monthly and seasonal variability did not reach the statistical significance $(\mathrm{p}>0.05)$.

\section{Discussion}

This retrospective study of OHCA affecting the population of southern Poland confirms a cir-

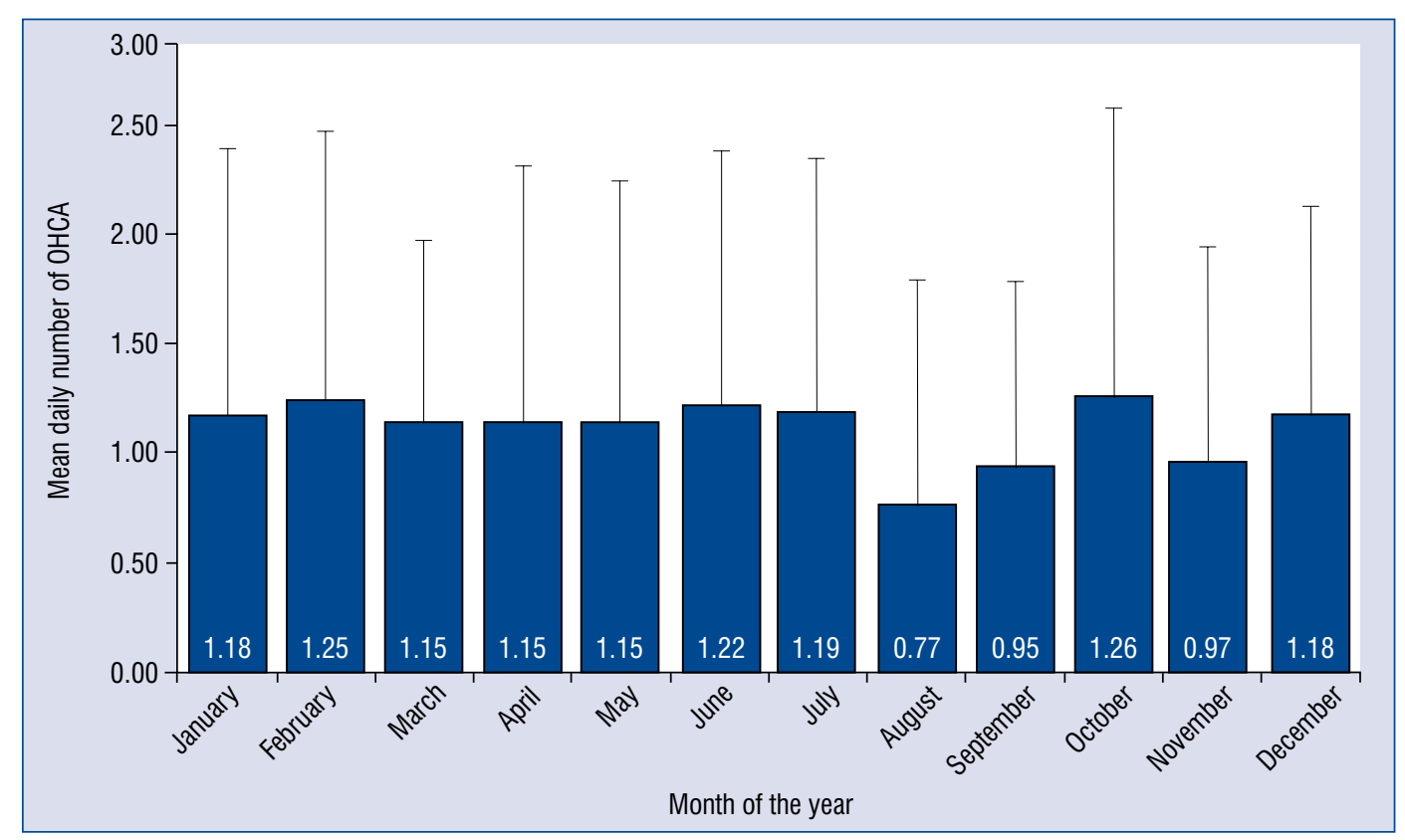

Figure 5. Monthly rhythm of mean daily number of cardiac arrests; $p=0.33$. August vs. February: $p=0.024 ;$ August vs. October: $p=0.027$. 


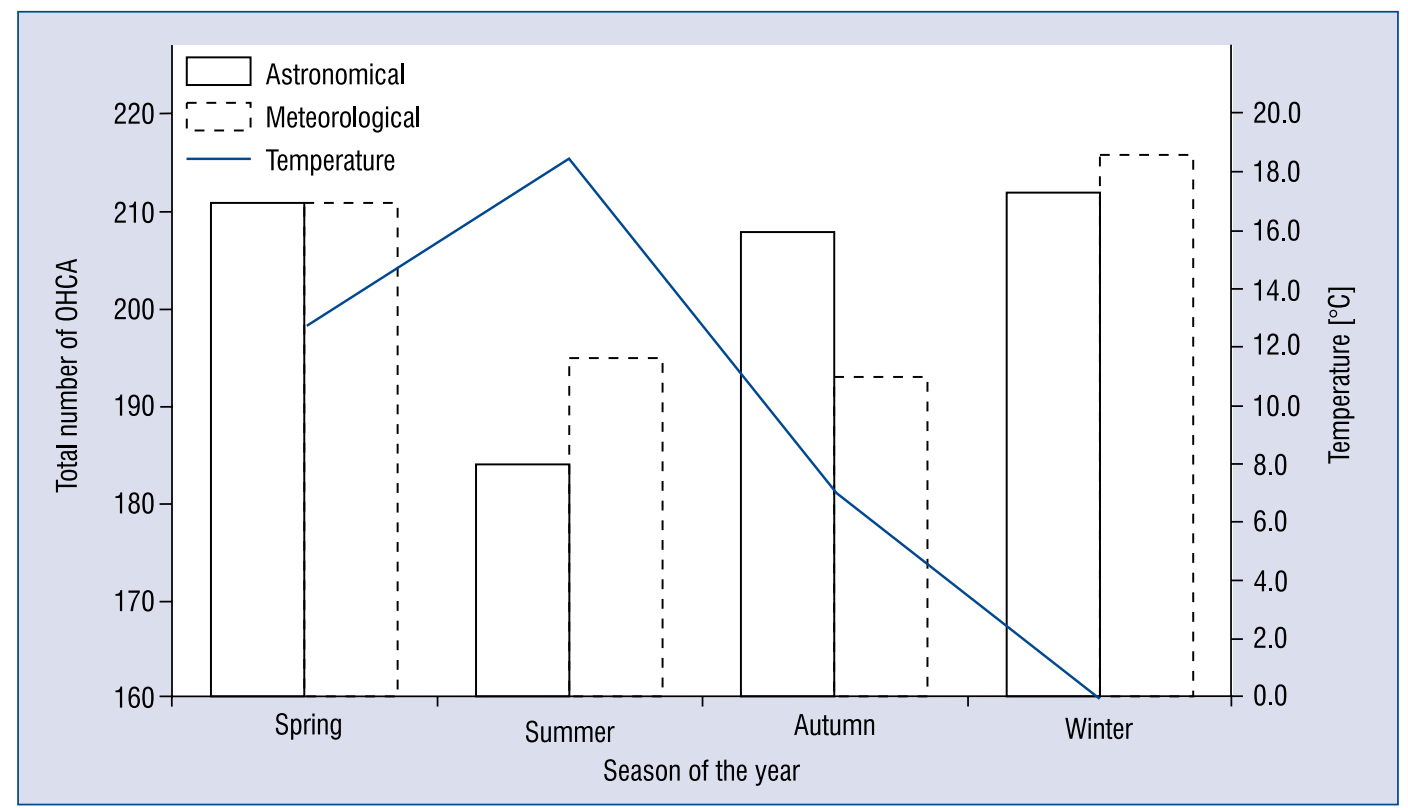

Figure 6. Seasonal rhythm of cardiac arrest with astronomical and meteorological division and with average temperatures during those seasons. Astronomical: $p=0.16$; Meteorological: $p=0.35$; Summer vs. Winter: $p=0.04$; Summer temperature vs. Winter temperature: $p=0.0001$.

cadian rhythm of OHCA occurrence, observed in previous studies. Analysis of circaseptan rhythm of events has emerged much less marked OHCA variability, with Friday being a day with the lowest case incidence. Moreover, monthly and seasonal variation of OHCA with respect to seasonal temperature was explored and this is the first report among Polish studies. The results of this work advances the knowledge about the chronobiology of OHCA in Poland and might serve as a basic source of information about the true situation of this phenomenon. To date, no previous studies have been conducted in this particular setting.

The incidence of OHCA presented in European studies range from 0.36 to $1.28 / 1000$ inhabitants per year $[1,3]$. In the present study a higher incidence of 1.56/1000 inhabitants per year was noticed, but even higher value was presented in another Polish study (1.7/1000 per year, 2.43 in men and 0.99 in women) [2]. The same tendency regarding gender was observed where the incidence rate is almost two times higher among men in comparison to women. The occurrence of $\mathrm{OHCA}$ increases with age, which is supported by our data, although there are visible differences between men and women. Women make up the minority of patients younger than 75 years and they reach the peak value of OHCA occurrence 5-10 years later than men.
Circadian variation of the occurrence of $\mathrm{OHCA}$ was widely described in the literature. The present results, in accordance with other studies, confirms the lowest occurrence of OHCA during night hours (from 00:00 to 06:00) and increasing rate of incidents in the early morning hours - the highest from 06:00 to 09:00 [9, 18]. In the majority of cases the occurrence curve presented two peaks [13-15, 18-20] in the morning (08:00-10:00) and in the late afternoon (16:00-20:00). This study observed three peaks: between 8.00 and $10.59 \mathrm{am}$, between 14.00 and 15.59 , less marked 18.00-21.59 and similar observation was made by Soo et al. [21]. The distribution of OHCA with the low occurrence rate during night hours and typical increase in the morning hours may be the result of diurnal changes in blood pressure $[4,5]$, vascular tone [5], heart rate, endothelial function [5], platelet aggregability [22], and catecholamines concentration [6] which all are potential triggers of acute myocardial infarction. The autopsy data suggests that the majority of sudden cardiac deaths are the consequence of acute myocardial infarction or ischemia and related arrhythmias. It is supported by the fact that the incidence of myocardial infarction also exhibits a morning time excess, occurring much more frequently during the 6.00-12.00 am time block. Similar patterns of frequency exist for other cardiovascular events, like pulmonary 
embolism or ischemic stroke [15]. Nevertheless, this trimodal phenomenon is difficult to explain, especially with respect to the afternoon and evening peaks. The observed variability could be driven both by patients who were found dead in the morning after some time of having a cardiac arrest and the patients who have died during the day and were found dead by family members returning home. The data concerning witnessed and non-witnessed OHCA were not analyzed, but unwitnessed cases were proven to occur more likely during the night and at private home than witnessed OHCA [18]. It might be a source of misclassification of time of arrest in the present study in some percentage of cases, but on the other hand it alone cannot explain the morning peak of OHCA.

Some previous studies showed statistically significant weekly variation of the occurrence of OHCA [9, 15, 23] although Nakanishi et al. [13] did not report such significance. If did, the majority indicated the highest number of OHCA was on Monday [9, 13, 14, 24]. Prior studies suggested a Monday excess for employed subjects $[9,25]$ nevertheless the present data do not confirm this observation, both in the subgroup of $<65$ years old as well as the older group. Though, a tendency was demonstrated for a higher incidence rate from Saturday to Monday. Allegra et al. [23] and Brooks et al. [15] presented the results where the highest number of OHCA appeared on Saturday. The day with the lowest occurrence rate varied depending on the study: Tuesday [9, 15, 23], Wednesday [13], Thursday [14], Saturday [24]. The most commonly observed increase of risk on Mondays could be the result of increased cortisol [6] levels induced by stress due to returning to work, but it does not explain the Saturday excess in this setting. The latter might be partly explained by the probable influence of participating in strenuous activities on weekends and altered medication compliance [23]. However, the abovementioned diverse observations of weekly OHCA variation may arise presumably from the diversity of the studied populations in terms of age distribution or behavioral patterns, like alcohol intake, leisure activities, and time and type of workload among others.

The seasonal variability of the occurrence of OHCA was studied in different places around the globe, e.g. Japan [13], Singapore [14], Sweden [9], United States of America and Canada [15]. The months with the highest number of OHCA were usually: December, January and February [9, 13, 15, 23, 24]. July and August turned out to have the lowest occurrence rate in the majority of compared studies [13, 14, 23, 24], which concurs with the present research. Exposure to low temperature is considered to be one of the main factors influencing cardiac arrest incidence, also it significantly determines morbidity and mortality of acute cardiovascular events. Some authors did not divide the year into seasons but compare the three warmest and coldest months showing $71.2 \%$ more OHCA during the coldest period [13]. Not all previous publications presented statistically significant variation between the months suggesting the impact of climate, geographic specificity, climate-related behavior on analyzed data [14]. Poland lies in a moderate climate zone with mixed continental and oceanic influences and it evidently differs from other countries located not only in equatorial or subtropical climate, but also European ones. Temperature differences during the year between seasons are marked, but there are some other factors potentially influencing the results like seasonal migration. Probably not only the absolute temperatures are essential but dayto-day or month-to-month temperature changes could also have a potential significance. Moreover, the present research indicates the importance of defining seasons precisely when comparing to other outcomes because the same data divided into astronomical or meteorological seasons could give different results and patterns.

There are only a few Polish publications considering the epidemiology of cardiac arrest but, according to available research, this study is the first presenting the results of diurnal, weekly and seasonal OHCA variability collectively with various whether indices. Gach et al. [2] analyzed a smaller population from 1-year period (2013) and reported similar diurnal variation in OHCA incidence, however significant discrepancy exists when comparing days of the week and months with the lowest and the highest OHCA frequencies (May and December, respectively and no statistical significance of weekly variation, the highest rate being on Tuesday). Presented dissimilarity strengthens the need for more and large-scaled research, although the influence of multiple population and territory specific factors affecting every result cannot be neglected.

\section{Limitations of the study}

The retrospective and observational nature of this study is one of the main limitations in the analysis, together with the lack of the possibility to collect more essential data (e.g. patient medical history, comorbidities or medical treatment). 
Neither analysis of the data concerning witnessed and non-witnessed OHCA nor the survival was considered. On the other hand emphasis of the characteristics of OHCA phenomenon in this subpopulation was sought in terms of various temporal and meteorological factors. Another limitation was the difficulty in the assessment of the precise time of event occurrence mainly due to the adopted methodology. The present study is also limited by the fact that the Opole district is a relatively small territory. However the observation that $63.7 \%$ of OHCAs took place in the urban area demonstrates the heterogeneity of this territory, which could result in a more accurate presentation of the phenomenon. The homogenous territory could result in a bias of selecting a specific group of patients. Thus, although we consider our data valuable, it still should be taken with caution and require both the amplification and confirmation in larger-scaled studies.

\section{Conclusions}

The studied population is characterized by circadian rhythm of OHCA incidence and less marked circaseptan differences in OHCA occurrence. These results are in agreement with the most of the previous reports. Seasonal differences in OHCA incidence was also observed, and this phenomenon may be affected by temperature. Moreover, OHCA incidence increases with patient age, but temporal variations in these events occur independent of age. This is the first Polish analysis of such a large group of cases, which also includes seasonal temperature data. We assume that it both constitutes the substantial source of knowledge as well as complements Polish experience in this research area, which had previously been rather scarce.

\section{Conflict of interest: None declared}

\section{References}

1. Bossaert LL, Perkins GD, Askitopoulou H, et al. ethics of resuscitation and end-of-life decisions section Collaborators. European Resuscitation Council Guidelines for Resuscitation 2015: Section 11. The ethics of resuscitation and end-of-life decisions. Resuscitation. 2015; 95: 302-311, doi: 10.1016/j.resuscitation.2015.07.033, indexed in Pubmed: 26477419.

2. Gach D, Nowak JU, Krzych $\mathrm{EJ}$. Epidemiology of out-of-hospital cardiac arrest in the Bielsko-Biala district: a 12-month analysis. Kardiol Pol. 2016; 74(10): 1180-1187, doi: 10.5603/ /KP.a2016.0086, indexed in Pubmed: 27221961.
3. Engdahl J, Holmberg M, Karlson BW, et al. The epidemiology of out-of-hospital 'sudden' cardiac arrest. Resuscitation. 2002; 52(3): 235-245, doi: 10.1016/s0300-9572(01)00464-6.

4. Hermida RC, Ayala DE, Portaluppi F. Circadian variation of blood pressure: the basis for the chronotherapy of hypertension. Adv Drug Deliv Rev. 2007; 59(9-10): 904-922, doi: 10.1016/j. addr.2006.08.003, indexed in Pubmed: 17659807.

5. Rudic RD. Time is of the essence: vascular implications of the circadian clock. Circulation. 2009; 120(17): 1714-1721, doi: 10.1161/ CIRCULATIONAHA.109.853002, indexed in Pubmed: 19858424.

6. Nicolau GY, Haus E, Popescu M, et al. Circadian, weekly, and seasonal variations in cardiac mortality, blood pressure, and catecholamine excretion. Chronobiol Int. 1991; 8(2): 149-159, indexed in Pubmed: 1797411.

7. Kanabrocki EL, Sothern RB, Bremner WF, et al. Weekly and yearly rhythms in plasma fibrinogen in hospitalized male military veterans. Am J Cardiol. 1995; 76(8): 628-631, indexed in Pubmed: 7677095.

8. Kubica A, Szczerbiński S, Kieszkowska M, et al. Wpływ czynników klimatycznych i chronologicznych na występowanie ostrych incydentów chorobowych. [The influence of climatic and chronological factors on the occurrence of acute disease events] Folia Cardiologica. 2014; 9: 263-266.

9. Herlitz J, Eek M, Holmberg M, et al. Diurnal, weekly and seasonal rhythm of out of hospital cardiac arrest in Sweden. Resuscitation. 2002; 54(2): 133-138, indexed in Pubmed: 12161292.

10. Ekelund U, Akbarzadeh M, Khoshnood A, et al. Likelihood of acute coronary syndrome in emergency department chest pain patients varies with time of presentation. BMC Res Notes. 2012; 5: 420, doi: 10.1186/1756-0500-5-420, indexed in Pubmed: 22871081.

11. Li Yi, Du T, Lewin MR, et al. The seasonality of acute coronary syndrome and its relations with climatic parameters. Am J Emerg Med. 2011; 29(7): 768-774, doi: 10.1016/j.ajem.2010.02.027, indexed in Pubmed: 20825896.

12. Phillips DP, Jarvinen JR, Abramson IS, et al. Cardiac mortality is higher around Christmas and New Year's than at any other time: the holidays as a risk factor for death. Circulation. 2004; 110(25): 3781-3788, doi: 10.1161/01.CIR.0000151424.02045.F7, indexed in Pubmed: 15596560.

13. Nakanishi N, Nishizawa S, Kitamura Y, et al. Circadian, weekly, and seasonal mortality variations in out-of-hospital cardiac arrest in Japan: analysis from AMI-Kyoto Multicenter Risk Study database. Am J Emerg Med. 2011; 29(9): 1037-1043, doi: 10.1016/j. ajem.2010.06.018, indexed in Pubmed: 20708890.

14. Ong MEh, Ng FSp, Yap S, et al. Temporal variation of out-ofhospital cardiac arrests in an equatorial climate. Open Access Emerg Med. 2010; 2: 37-43, indexed in Pubmed: 27147836.

15. Brooks SC, Schmicker RH, Rea TD, et al. ROC Investigators. Out-of-hospital cardiac arrest frequency and survival: evidence for temporal variability. Resuscitation. 2010; 81(2): 175-181, doi: 10.1016/j.resuscitation.2009.10.021, indexed in Pubmed: 19942338.

16. Boczar D, Molodowicz M, et al. Ludność, ruch naturalny i migracje w województwie opolskim w 2006 r. [Population, vital statistics and migration of population in opolskie voivodship in 2006]. Urząd Statystyczny we Wrocławiu Wydział Poligrafii w Legnicy. Polisch. 2017: 7-20.

17. Molodowicz M, et al. Ludność, ruch naturalny i migracje w województwie opolskim w 2007 r. [Population, vital statistics and migration of population in opolskie voivodship in 2007]. 
Urząd Statystyczny we Wrocławiu Wydział Poligrafii w Legnicy. Polish. 2008: 7-22.

18. Karlsson LIM, Wissenberg M, Fosbøl EL, et al. Diurnal variations in incidence and outcome of out-of-hospital cardiac arrest including prior comorbidity and pharmacotherapy: a nationwide study in Denmark. Resuscitation. 2014; 85(9): 1161-1168, doi: 10.1016/j. resuscitation.2014.06.012, indexed in Pubmed: 24971509.

19. Lateef F, Ong MEH, Alfred T, et al. Circadian rhythm in cardiac arrest: the Singapore experience. Singapore Med J. 2008; 49(9): 719-723, indexed in Pubmed: 18830548.

20. Peckova M, Fahrenbruch CE, Cobb LA, et al. Circadian variations in the occurrence of cardiac arrests: initial and repeat episodes. Circulation. 1998; 98(1): 31-39, indexed in Pubmed: 9665057.

21. Soo LH, Gray D, Young T, et al. Circadian variation in witnessed out of hospital cardiac arrest. Heart. 2000; 84(4): 370-376, indexed in Pubmed: 10995402.
22. Tofler GH, Brezinski D, Schafer AI, et al. Concurrent morning increase in platelet aggregability and the risk of myocardial infarction and sudden cardiac death. N Engl J Med. 1987; 316(24): 1514-1518, doi: 10.1056/NEJM198706113162405, indexed in Pubmed: 3587281.

23. Allegra JR, Cochrane DG, Allegra EM, et al. Calendar patterns in the occurrence of cardiac arrest. Am J Emerg Med. 2002; 20(6): 513-517, indexed in Pubmed: 12369023.

24. Peckova M, Fahrenbruch C, Cobb L, et al. Weekly and seasonal variation in the incidence of cardiac arrests. Am Heart J. 1999; 137(3): 512-515, doi: 10.1016/s0002-8703(99)70507-7.

25. Arntz HR, Willich SN, Schreiber C, et al. Diurnal, weekly and seasonal variation of sudden death. Population-based analysis of 24,061 consecutive cases. Eur Heart J. 2000; 21(4): 315-320, doi: 10.1053/euhj.1999.1739, indexed in Pubmed: 10653679 . 